\title{
Circadian Molecular Clocks Tick along Ontogenesis
}

\author{
A. SUMOVÁ, Z. BENDOVÁ, M. SLÁDEK, R. EL-HENNAMY, K. MATĚJŮ, \\ L. POLIDAROVÁ, S. SOSNIYENKO, H. ILLNEROVÁ
}

Institute of Physiology, Academy of Sciences of the Czech Republic, v.v.i., Prague, Czech Republic

Received February 15, 2008

Accepted April 16, 2008

On-line May 13, 2008

\section{Summary}

The circadian system controls the timing of behavioral and physiological functions in most organisms studied. The review addresses the question of when and how the molecular clockwork underlying circadian oscillations within the central circadian clock in the suprachiasmatic nuclei of the hypothalamus (SCN) and the peripheral circadian clocks develops during ontogenesis. The current model of the molecular clockwork is summarized. The central SCN clock is viewed as a complex structure composed of a web of mutually synchronized individual oscillators. The importance of development of both the intracellular molecular clockwork as well as intercellular coupling for development of the formal properties of the circadian SCN clock is also highlighted. Recently, data has accumulated to demonstrate that synchronized molecular oscillations in the central and peripheral clocks develop gradually during ontogenesis and development extends into postnatal period. Synchronized molecular oscillations develop earlier in the SCN than in the peripheral clocks. A hypothesis is suggested that the immature clocks might be first driven by external entraining cues, and therefore, serve as "slave" oscillators. During ontogenesis, the clocks may gradually develop a complete set of molecular interlocked oscillations, i.e., the molecular clockwork, and become self-sustained clocks.

\section{Key words}

Circadian clock - Ontogenesis - Suprachiasmatic nucleus • Peripheral clock • Clock gene

\section{Corresponding author}

A. Sumová, Institute of Physiology, Academy of Sciences of the Czech Republic, Vídeňská 1083, 14220 Praha 4, Czech Republic.

E-mail: sumova@biomed.cas.cz

\section{Introduction}

The circadian system has evolved as an adaptation to cyclic changes in light and darkness due to the Earth's rotation that occurs within a period of solar day, i.e., 24 hours. It ensures the proper timing of vital processes in most organisms studied thus far. In mammals, the circadian system consists of a central clock in the brain and numerous peripheral clocks that are subordinate to the central clock. Via the molecular clockwork in cells, the clocks generate circadian rhythmicity, which controls bodily functions through rhythmic regulation of gene transcription. The rhythmicity is thus manifested at the behavioral as well as at the physiological levels. The mammalian central clock is strategically located in the suprachiasmatic nucleus (SCN) of the ventral hypothalamus just above the optic chiasm. It receives photic input from the retina, which synchronizes it with the $24-\mathrm{h}$ day. The SCN is a paired organ, and each of the two nuclei is composed of about 10000 mutually interconnected cells (for review see Moore et al. 2002, Lee et al. 2003). The peripheral clocks in mammals have lost their photosensitivity during evolution. They are synchronized with the 24-h day mostly via outputs from the central SCN clock, as well as by their local environment (Hastings et al. 2003, Yoo et al. 2004). The ontogenetic development of the mammalian circadian system has already been the subject of an extensive review (Weinert 2005). This mini-review mainly summarizes recent data that addresses the crucial question of when and how the mammalian circadian molecular clockwork develops during ontogenesis. Are the central and peripheral clocks functional at the time of 
birth? Do they develop even earlier, i.e., during the fetal stage? Data has recently accumulated to suggest that, although mammalian circadian clocks are genetically equipped to generate rhythmicity well before birth, they undergo a gradual postnatal development in order to function adequately.

\section{The molecular clock within a single cell}

Cells in the mammalian body are equipped with a set of genes that are indispensable for circadian clock function. The principles of circadian rhythmicity generation have been partly ascertained at the molecular level and are similar for the central and peripheral clocks. The basic components of the clockwork are the clock genes that encode clock proteins. Malfunction or absence of the clock components render severe abnormalities in circadian rhythmicity (Bae et al. 2001, van der Horst et al. 1999, Zheng et al. 2001). The abnormalities may range from lengthening or shortening of the circadian period to complete arrhythmicity. A contemporary model of the molecular core clockwork presumes that rhythmical expression of clock genes and their proteins drives the circadian clock in a cell-autonomic fashion (for review see Fu and Lee 2003, Ko and Takahashi 2006, Reppert and Weaver 2001). In principle, clock proteins CLOCK and BMAL1 serve as transcriptional activators that switch on the transcription of genes that contain Ebox response elements (CACGTG) in their promoters. Both of these proteins contain a basic helix-loop-helix DNA-binding domain and two PAS (Per-Arnt-Sim) protein interaction domains. E-boxes are present in the promoters of the clock genes Perl,2 and Cry1,2 and two orphan nuclear receptors Rev-erb $\alpha$ and Rora, as well as in the promoters of the clock-controlled genes, i.e., the genes that are not part of the core clockwork, but are controlled by it and thus transmit the rhythmical signal outside of the clock. After the CLOCK:BMAL1 heterodimer switches on transcription of Perl,2, Cry 1,2 clock genes, the proteins corresponding to these genes are formed with a clock protein-specific delay. The PER1,2 and CRY1,2 proteins accumulate in the cytoplasm and form homo- and heterodimers via their PAS domains. The dynamics of this checkpoint are controlled by posttranslational modifications of the clock proteins, mainly by phosphorylation and subsequent proteasomal degradation. PER protein phosphorylation by CASEIN KINASE $1 \varepsilon(\mathrm{CKI} \varepsilon)$ and CKI $\delta$ facilitates PER1 and PER2 ubiquitinylation and degradation and masks their nuclear localization signals. Consequently, the entry of the PER:CRY heterodimer into the nucleus is delayed (Lee $e t$ al. 2001, Lowrey et al. 2000, Akashi et al. 2002). This may be a crucial step for maintaining the circadian period of the molecular clock. After entering the nucleus, the PER:CRY heterodimers inhibit CLOCK:BMAL1 mediated transcription, most likely by mechanisms involving directed histone deacetylation and other chromatin modification (Etchegaray et al. 2003). Later on, PER:CRY repression is relieved by degradation of PERs and CRYs. The rhythmical transcription of the CLOCK:BMAL1 transcription activator complex is controlled via circadian oscillations in the transcription of clock gene Bmall. REV-ERB $\alpha$ and RORA compete to bind to ROR-response elements in the Bmall promoter, and repress or activate its transcription, respectively (Shearman et al. 2000, Preitner et al. 2002, Sato et al. 2004). These interlocked positive and negative transcriptional-translational feedback loops repeat with a circadian period and thus form the basis for a selfsustained circadian clock.

However, recent findings suggest that the core clockwork mechanism might be much more complex and the current model may represent only a part of the complete system. It is plausible that not only more genes, but even additonal mechanisms not considered in the current feedback loop model, may be involved. For example, miRNA, namely miR-219, has recently been implicated in the regulation of the central circadian clock (Cheng et al. 2007). miRNAs are small molecules that act as potent silencers of gene expression via translational repression of mRNA degradation. miR-219 is a target of the CLOCK:BMAL1 complex and exhibits robust circadian rhythms of expression as a clock-regulated gene. Moreover, in vivo knock-down of miR-219 lengthens the circadian period in a manner similar to a knock-out of the clock gene Clock. Translation control via miRNAs may, therefore, represent a novel regulatory level of the circadian clock. Another novel regulatory mechanism might be based on the finding that bZIP transcription factor E4BP4 is a key negative component of the circadian clock (Ohno et al. 2007). Moreover, three recent reports confirmed the importance of targeted protein degradation as a key feature of the circadian clock (Siepka et al. 2007, Busino et al. 2007, Godinho et al. 2007). They revealed that the clock protein CRY is targeted for degradation by a member of F box family of ubiquitin E3 ligases, FBXL3. Overtime (Siepka et al. 2007) and after hours (Godinho et al. 2007) mutations 
both lie in the region of FBXL3 that binds to CRY. Due to these mutations, binding of FBXL3 to CRY is disrupted, CRY degradation is prevented and the duration of its repressive function on clock gene activation is prolonged. Therefore, mice with a targeted mutation of FBXL3 have a longer circadian period than wild-type mice. Although the mechanisms of the degradation pathways have not been fully ascertained, targeted degradation is likely to control not only the rate at which clock protein complexes accumulate in the cytoplasm, but also the rate of their degradation.

Although the basic principles of the core clockwork seem to be conserved across the central and peripheral clocks, they might not be absolutely identical. In contrast to peripheral clocks, the central clock within the SCN is formed of a web of inter-connected cellautonomous oscillators (see below). Recent data have demonstrated that the inter-cellular clock mechanisms may significantly contribute to the robustness of the clock system (Liu et al. 2007). The oscillator network interactions in the SCN can partly compensate for Perl or Cryl deficiency and preserve sustained rhythmicity in behavior and in vitro in the SCN slices of Perl or Cryl mutant mice. In contrast, Perl and Cryl genes are implicitly required for sustained rhythms in peripheral tissues, cells and dissociated SCN neurons (Liu et al. 2007). Therefore, a new model that is specific for the central SCN clock is needed to incorporate the ability of inter-cellular coupling among the SCN neurons to confer the robustness of molecular oscillations.

\section{SCN clock: a single cell oscillator or a web of coupled oscillators?}

To function properly as a master clock, the SCN must not only be able to generate circadian oscillations, but must also entrain the oscillations at single cell level to cyclically occurring cues and transmit the synchronized rhythmic information to the rest of the body. These tasks are highly dependent upon inter-neuronal coupling within the SCN. In the adult SCN, information regarding photic entraining cues is first processed by a set of neurons located in the retinorecipient zone of the SCN. In rodents, this zone is called the ventrolateral (VL) part or the core of the SCN. Thereafter, the information is sent via intraSCN coupling pathways to the non-photosensitive cells located mostly within the dorsomedial (DM) part or the shell of the SCN (Yamaguchi et al. 2003, Yan and Okamura 2002, Yan and Silver 2004, Yan et al. 1999).
Inter-cellular communication between clusters of SCN cells has recently been considered to be important for entrainment of the central clock to a change in day length, i.e., in the photoperiod (Inagaki et al. 2007, VanderLeest et al. 2007). The mechanism by which the coupling is accomplished is not well understood. Several mechanisms underlying the intercellular synchrony have been considered, namely electrical coupling (Aton and Herzog 2005) and coupling by neurotransmitters, such as vasoactive intestinal polypeptide (VIP) (Harmar et al. 2002, Aton et al. 2005, Maywood et al. 2006) and gamma aminobutyric acid (GABA) (Albus et al. 2005, Aton et al. 2006).

Recent findings support the idea that intercellular coupling is crucial not only for entrainment and transmission of the synchronized output signals out of the clock, but also for the time-keeping mechanism per se. In particular, the VIP signaling through the VIPR2 receptor has been shown not only to contribute to synchrony between cells, but also to help maintain a robust rhythmicity in individual SCN neurons. In $\mathrm{Vip}^{-{ }^{--}}$and $V i p r 2^{-/}$mice, the circadian firing rhythm was abolished in about half of all SCN neurons (Aton et al. 2005). Similarly, the rhythmicity was disrupted in cells within the SCN organotypic slices from Vipr $2^{-/}$mice carrying Per1::luciferase and Per1::GFP reporter transgenes as reporters of activity within the core circadian feedback loop (Maywood et al. 2006). Recently, it has been shown that coupling between single cell $\mathrm{SCN}$ oscillators may amplify and stabilize unstable component oscillators, and, therefore, establish a more reliable rhythmicity at the SCN and behavioral level (Liu et al. 2007, To et al. 2007). Thus, the coupling between individual rhythmic cells is likely to contribute the autonomous time-keeping mechanism and ensure stability of the central clock.

\section{Development of the central SCN clock}

From the data summarized above, it is obvious that the adult central clock is not only a simple sum of self-oscillating neurons, but is rather a well organized entity. The multi-level organization includes coupling between individual neurons as well as coupling between the defined subdivisions of the nucleus. Therefore, development of the central clock within the SCN obviously does not depend only on the presence of individual components of the molecular core clockwork and the ability of single cells to oscillate, but also on development of a hierarchical organization of the 
nucleus. Only maturation of the complex clock enables the development of synchronized oscillatory signaling from the central clock to the rest of the body. In this context, data regarding the morphological development of the mammalian $\mathrm{SCN}$ might be highly relevant.

Morphologically, the rodent SCN develops gradually (Moore 1991). Gestational periods among different rodent species differ and therefore, for simplification, most of the further discussion relates to development of the rat SCN. In the rat, the prenatal period lasts about 22 days. Neurogenesis of the SCN begins on embryonic day (E) 14 and continues through E17 from a specialized zone of the ventral diencephalic germinal epithelium as a component of periventricular cell groups. Neurons of the VL SCN are generated at E15 - E16 and those of the DM SCN at E16 - E17. The neurogenesis is completed at E18, but the morphological maturation of the SCN neurons gradually proceeds until postnatal day (P) 10. Synaptogenesis in the $\mathrm{SCN}$ is a slower process; at E19, only very sparse synapses may be observed. It begins to progress only in the late prenatal and early postnatal periods, and then increases noticeably from P4 to P10 (Weinert 2005). Therefore, during the prenatal period, the SCN neurons are present but the multi-level inter-cellular coupling may not yet be functional. The coupling strengthens during the first postnatal week and, the rat $\mathrm{SCN}$ is fully developed to its full complexity only at P10.

Intrinsic rhythms in the SCN may appear as early as the late embryonic stage. A day-night variation in metabolic activity monitored by a 2-deoxyglucose uptake was detected in the fetal rat SCN from E19 through E21 (Reppert and Schwartz 1984), in the Avp mRNA level at E21 (Reppert and Uhl 1987) and in the firing rate of the SCN neurons at E22 (Shibata and Moore 1987). All these rhythms are supposed to be driven by the SCN clock in adults, and the rodent fetal clock has therefore been considered to be functionally developed well before birth. However, direct evidence that the above mentioned fetal SCN rhythms are indeed driven by the molecular core clockwork is lacking. Alternatively, the observed rhythmicity might arise from cyclically appearing maternal cues, which impinge on fetal SCN neurons and driving the oscillations in a "slave" oscillator-like fashion. Such maternal "zeitgebers" might trigger the rhythm in neuronal activity, as reflected in the rhythms in firing rate and metabolic activity, as well as in gene transcription, as is the case with the observed rhythm in $A v p$ mRNA levels. It is relevant to note that transcription of $A v p$ might be regulated not only by the clockwork via activation of the E-box sequence in its promoter (Jin et al. 1999), but also via activation of CRE (Iwasaki et al. 1997, Burbach et al. 2001) and AP1 (Burbach et al. 2001) elements by a non-clock-related mechanism. Moreover, recent data using detection of heteronuclear RNA as a nascent transcript, which is a more reliable marker of transcriptional rate than detection of mRNA, did not reveal any circadian rhythmicity in transcription of the Avp gene in the rat SCN at E20. However, the expression was rhythmic at P1 (Kováćiková et al. 2006).

A solution to the question of whether the central clock is functional before birth might come from studies on the development of the molecular core clockwork mechanism. According to the current model described above, the circadian rhythms in the levels of the clock gene transcripts and protein products are essential for the molecular timekeeping mechanism. Therefore, several groups of researchers have measured the daily profiles of clock gene expression in the rat SCN by in situ hybridization, but outcome of these studies was ambiguous. Ohta et al. reported high amplitude rhythms of Perl and Per 2 mRNA in the fetal rat SCN at E20 (Ohta et al. 2002, 2003). Other authors studied the daily profiles of Per1, Per2, Cryl and Bmall mRNA at E19, i.e., at the embryonic day when the fetal rat SCN is already formed (Moore 1991) and the rhythm in metabolic activity present (Reppert and Schwartz 1984). However, none of the above-mentioned clock genes were expressed rhythmically at that embryonic stage (Sládek et al. 2004). Moreover, levels of clock gene proteins PER1, PER2 and CRY1 not only did not exhibit any circadian variation, but were in fact undetectable at E19 (Sládek et al. 2004). These data suggest that at this stage of fetal development, the SCN circadian clock might not be able to generate synchronized oscillations. The same authors performed a detailed developmental study and found that at E20, some of the rhythms were just about beginning to form, but the amplitude of rhythmicity was very low or did not reach a significant level (Kováčiková et al. 2006). Rhythms in clock gene expression developed gradually during the postnatal period, and adult-stage-like amplitudes were achieved only at P10 (Kováčiková et al. 2006) (Fig 1). Similarly, molecular oscillations equivalent to those observed in adults were not detected in the fetal hamster SCN (Li and Davis 2005). In mice, Shimomura et al. found a significant oscillation in Perl but not in Per2 mRNA in the SCN at E17, and the amplitude of the oscillations increased progressively with 
postnatal age (Shimomura et al. 2001).

Using this approach, it was possible to study the development of synchronized rhythmicity, but not the development of single cell rhythmicity. Low amplitude rhythms in clock gene expression might already be present in individual SCN neurons, but they may not yet be mutually synchronized due to insufficient synapses in the embryonic SCN (Moore 1991). The increase in the amplitude of the rhythms in clock gene expression correlated well with synaptogenesis within the SCN. Therefore, it is plausible that mutual synchronization of the SCN neurons due to developing synapses may account for the gradual rise in the amplitude of clock gene oscillations. Theoretically, development of the synapses might also be conditional for the oscillations. Daily profiles of clock gene expression in the rat SCN at E19 seem to support the idea of undeveloped molecular oscillations in individual neurons rather than the idea of fully developed but desynchronized oscillations, since levels of constitutively expressed Perl, Cryl and Bmall genes at E19 corresponded either to the minimum or maximum, but not to the mean of their P3 values. Moreover, at E19, not only rhythms in clock gene mRNA levels, but also protein products PER1, PER2 and CRY1 were undetectable. In fact, no PER1, PER2 and CRY limmunoreactive cells were detected in the fetal SCN at any circadian time (Sládek et al. 2004). The absence of the basic components of the molecular core clockwork is rather in favor of the hypothesis that the mechanism enabling the rhythmic expression of clock genes may not yet be mature at E19. However, the possibility cannot be ruled out that only a very small proportion of the SCN cells is rhythmic during the fetal stage, and that the number of rhythmic cells increases due to development of synaptic communication between these rhythmic cells and the non-rhythmic ones. The methodological approach used in the above-mentioned studies would not detect a very low oscillating signal, which could potentially arise from a few SCN cells.

The use of newly introduced experimental tools, such as transgenic animals, will be necessary for addressing these issues in the future. In SCN slices explanted from transgenic animals, it is possible to detect rhythms in clock gene expression with a single cell resolution. However, even in the case of detection of a significant rhythm in clock gene expression at a single cell level during the fetal stage, the question still remains as to whether these rhythms are indeed reliable markers of a functional circadian clock. If so, individual cellular oscillators without any coupling must be able to drive synchronized rhythmicity. However, such characteristics have not been observed in in vitro cell lines that are devoid of inter-cellular coupling like the fetal clock. Without entraining cues, these cells are desynchronized or arrhythmic. As soon as the cultured cells are subjected to a "zeitgeber", e.g., to serum shock, the cells become synchronized and exhibit synchronized rhythmicity (Balsalobre et al. 1998). Therefore, the question of whether the fetal SCN cells are able to maintain oscillations, or whether the oscillations would soon be dampened in the isolated SCN may still remain. The possibility that other mechanisms besides the molecular clockwork might drive the SCN rhythmicity during late embryonic development should be considered. For example, maternal cues, such as dopamine or melatonin, might directly trigger the fetal SCN rhythm in metabolic activity (Davis and Mannion 1988, Weaver et al. 1995). Complete lesions of the maternal SCN at E7 disrupt rhythms in SCN glucose utilization in rat fetuses (Reppert and Schwartz 1986). This disruption might be due to desynchronization among the fetuses, but also might be due to the lack of a rhythmical input to the slave fetal clock. Strikingly, a periodic feeding cue delivered to SCN-lesioned pregnant rats is sufficient to entrain the fetal SCN clock (Weaver and Reppert 1989). The fetal clock is therefore sensitive to feeding cues in a way similar to adult peripheral clocks, but not the adult SCN clock. These observations suggest that multiple and more complex pathways mediate rhythmic information to the fetal SCN clock as compared to the adult SCN clock. They also indicate that formal properties of the fetal and of the postnatal SCN clock may differ. Therefore, the possibility cannot be excluded that during ontogenesis, the SCN clock develops spontaneously from a slave oscillator at the prenatal stage to a master clock at the postnatal stage.

More strikingly, the restructuring of the slave oscillator to the master clock may occur spontaneously without entraining cues driven by the maternal SCN. Surgical ablation of the maternal SCN did not prevent development of the clock during the postnatal period (Reppert and Schwartz 1986, Davis and Gorski 1988). Moreover, genetic ablation of functional central as well as peripheral maternal clocks did not prevent spontaneous development of the clocks, since heterozygous off-spring of $\mathrm{mPer} 1^{\text {Brdml }} / \mathrm{Per} 2^{\text {Brdml }}$ and $m P e r 2^{\text {Brdml }} / \mathrm{Cry} 1^{-/}$double mutant arrhythmic females crossed with wild-type males developed circadian rhythm in locomotor activity. 
However, within a litter, pups were less synchronized than pups born to wild-type controls (Jud and Albrecht 2006). Also, transplantation of fetal SCN tissue to arrhythmic SCN-lesioned animals leads to a recovery in the circadian rhythm of locomotor activity (Ralph et al. 1990). Therefore, development of the circadian clock appears to be genetically predetermined.

\section{Peripheral clocks during ontogenesis}

Studies on the development of peripheral clocks have only recently commenced after the finding that rhythms in clock gene expression are detectable in cells of the peripheral organs, and are therefore not unique to the central SCN clock (Abe et al. 2001, Balsalobre 2002, Schibler and Sassone-Corsi 2002). Two methodological approaches for these studies were used. In the first approach, daily profiles of clock gene expression within a peripheral tissue sampled throughout the circadian cycle were examined. In the rat heart, circadian rhythms in the expression of clock genes Per1, Per2 and Bmall and a clock-controlled gene $\mathrm{Dbp}$ were not detected by Northern blot analysis on P2 (Sakamoto et al. 2002). Expression of Per1, Bmall and Dbp began to be rhythmic between P2 and P5, but expression of Per2 did not exhibit any rhythmicity until P14. Similarly, in the rat liver, clock gene expression as determined by RT-PCR developed gradually during postnatal ontogenesis (Sládek et al. 2004) (Fig.1). At E20, only Rev-erb $\alpha$ mRNA exhibited a significant, high amplitude circadian oscillation, but the expression of Per1, Per2, Cry1, Bmal1 and Clock mRNA did not. Even at P2, Rev-erba was still the only gene expressed rhythmically with high amplitude. At P10 Perl mRNA and at P20 Per2 and Bmall also began to be expressed in a circadian way. Only as late as at P30, all of the studied clock genes were expressed rhythmically in an adult-like pattern (Sládek et al. 2004). Development of the molecular oscillations in the liver was therefore similar to that in the heart. Apparently, rhythms in synchronized clock gene expression develop earlier in the central SCN clock (see above) than in peripheral oscillators. The stable detection of the high-amplitude rhythm in Rev-erba expression throughout ontogenesis rules out the possibility that the lack of rhythmicity in the early development is due to desynchronization of oscillating cells in the liver. Unlike the SCN clock cells, the peripheral oscillating cells are not mutually interconnected via synapses and are likely to be synchronized by rhythmic humoral or neuronal cues

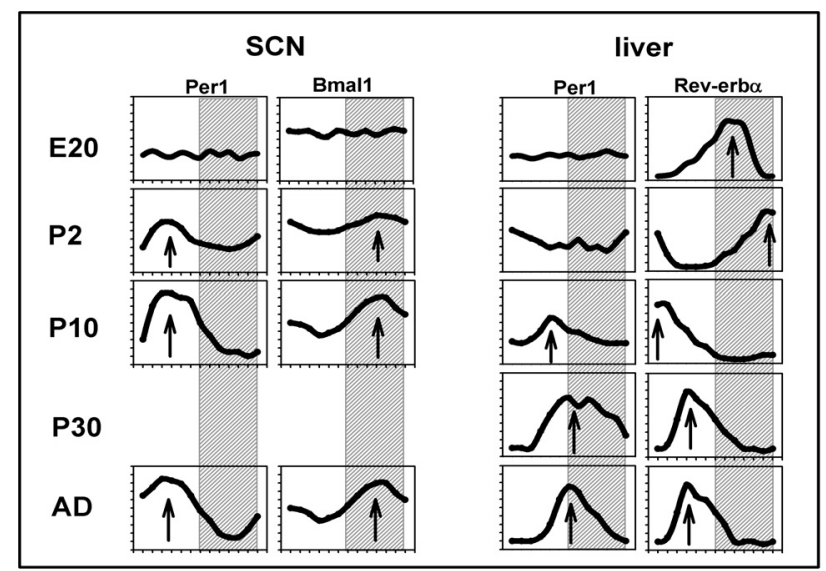

Fig. 1. Schematic drawings of development of the circadian clocks in the rat. Daily profiles of clock gene Per1 and Bmal1 mRNA in the SCN and Per1 and Rev-erba in the liver are depicted in 20-day-old embryos (E20), in pups at postnatal day 2 (P2), $\mathrm{P} 10, \mathrm{P} 30$ and in adult rats. $\mathrm{X}$ axis represents day time with the shaded area defining night hours. $Y$ axis represents relative mRNA levels. Drawings are based on results published previously in Sládek et al. (2004), Kováčiková et al. (2006) and Sládek et al. (2007).

impinging upon individual cells. The significant rhythm in Rev-erb $\alpha$ expression in the absence of rhythms in other clock genes during ontogenesis may give us clues regarding the mechanism that underlies peripheral clock development. During an early developmental stage, rhythmic expression of Rev-erb $\alpha$ might be triggered by mechanisms other than E-box mediated induction. Apart from the E-box, the Rev-erb $\alpha$ promoter contains other response elements that may be responsible for switching on/off gene transcription, namely Rev-DR2/RORE, DBPE/D-box etc. (Adelmant et al. 1996, Raspe et al. 2002, Yamamoto et al. 2004). The rhythmically appearing mediators may activate transcription of Reverba by stimulation of some of these elements independently of the core clockwork. Moreover, it is tempting to speculate that the rhythmic expression of Rev-erb $\alpha$ might trigger the newly appearing rhythms in clock gene expression, since a constant phase relationship between rhythms in the expression of Rev-erb $\alpha$ and other clock genes is maintained during different developmental stages (Sládek et al. 2004) (Fig.1). Therefore, theoretically, a peripheral clock may function as a slave oscillator during early ontogenesis, and may only later, with the development of clock gene oscillations, become a self-autonomous clock.

Importantly, phases of the rhythms in clock gene expression in the liver (Sládek et al. 2007) as well as in the heart (Sakamoto et al. 2002) change during development. The acrophase of these rhythms shifts in a coordinated 
manner so that the expressions of individual clock genes keep stable phase relationships throughout development (Fig.1). Feeding regimes accompanied by behavioral activity may account for these phase changes. Mothers feed their pups mostly during the daytime; therefore, during the period of maternal breast feeding, pups are diurnal rather than nocturnal in their food consumption (Weinert 2005). The nocturnal feeding pattern develops during the weaning period, but it is preceded by a period when pups still suckle some maternal milk during the daytime and consume solid food during the nighttime. These changes in feeding behavior appear to be mirrored in changing phases of the rhythms in clock gene expression.

Recently, another approach was used for studying the ontogenesis of oscillations in clock gene expression (Saxena et al. 2007). In vivo rhythms in bioluminiscence were monitored in utero in the fetuses of transgenic rats carrying Per1::luciferase transgene throughout the whole gestational period (Saxena et al. 2007). The bioluminiscence increased dramatically at E10 and continued to increase progressively until birth. Diurnal fluctuations in Perl expression in the whole body were already suggested prior to birth. From this study, it is not apparent which parts of the fetal body might account for the whole-fetal bioluminiscence recorded in vivo or for the suggested day-night differences observed. It is possible that some peripheral clocks may start to exhibit circadian rhythms in Perl expression before birth. Tissue-specific differences in the development of molecular oscillations in peripheral clocks are suggested.

\section{Conclusions}

The data summarized in this mini-review cannot definitively answer the question of exactly when the central and peripheral clocks develop during the mammalian ontogenesis. Depending on the methods used, different results have been produced; therefore, more studies are still needed. However, most results support the hypothesis that synchronized oscillations in clock gene expression develop gradually during ontogenesis, and development extends well into the postnatal period. It is feasible that the ability to function as a self-sustained clock may develop gradually, and that the immature clock may function first as a "slave" oscillator. Only later, with the development of a complete set of molecular oscillations, may it become a selfsustaining clock. Such development occurs earlier in the central SCN clock than in peripheral clocks.

\section{Conflict of Interest}

There is no conflict of interest.

\section{Acknowledgements}

The authors are supported by the Grant Agency of the Czech Republic, grant No. 309080503; Grant Agency of the Academy of Sciences of the Czech Republic, grant No. IAA500110605; by Research Projects AV0Z 50110509, and LC554; and by the $6^{\text {th }}$ Framework Project EUCLOCK 018741.

\section{References}

ABE H, HONMA S, NAMIHIRA M, MASUBUCHI S, IKEDA M, EBIHARA S, HONMA K: Clock gene expressions in the suprachiasmatic nucleus and other areas of the brain during rhythm splitting in CS mice. Mol Brain Res 87: 92-99, 2001.

ADELMANT G, BEGUE A, STEHELIN D, LAUDET V: A functional Rev-erb alpha responsive element located in the human Rev-erb alpha promoter mediates a repressing activity. Proc Natl Acad Sci USA 93: 3553-3558, 1996.

AKASHI M, TSUCHIYA Y, YOSHINO T, NISHIDA E: Control of intracellular dynamics of mammalian period proteins by casein kinase I epsilon (CKI epsilon) and CKI delta in cultured cells. Mol Cell Biol 22: 1693-1703, 2002.

ALBUS H, VANSTEENSEL MJ, MICHEL S, BLOCK GD, MEIJER JH: A GABAergic mechanism is necessary for coupling dissociable ventral and dorsal regional oscillators within the circadian clock. Curr Biol 15: 886-893, 2005.

ATON SJ, COLWELL CS, HARMAR AJ, WASCHEK J, HERZOG ED: Vasoactive intestinal polypeptide mediates circadian rhythmicity and synchrony in mammalian clock neurons. Nat Neurosci 8: 476-483, 2005.

ATON SJ, HERZOG ED: Come together, right ... now: synchronization of rhythms in a mammalian circadian clock. Neuron 48: 531-534, 2005. 
ATON SJ, HUETTNER JE, STRAUME M, HERZOG ED: GABA and $\mathrm{G}_{\mathrm{i} / \mathrm{d}}$ differentially control circadian rhythms and synchrony in clock neurons. Proc Natl Acad Sci USA 103: 19188-19193, 2006.

BAE K, JIN X, MAYWOOD ES, HASTINGS MH, REPPERT SM, WEAVER DR: Differential functions of mPer1, mPer2, and mPer3 in the SCN circadian clock. Neuron 30: 525-536, 2001.

BALSALOBRE A: Clock genes in mammalian peripheral tissues. Cell Tissue Res 309: 193-199, 2002.

BALSALOBRE A, DAMIOLA F, SCHIBLER U: A serum shock induces circadian gene expression in mammalian tissue culture cells. Cell 93: 929-937, 1998.

BURBACH JP, LUCKMAN SM, MURPHY D, GAINER H: Gene regulation in the magnocellular hypothalamoneurohypophysial system. Physiol Rev 81: 1197-1267, 2001.

BUSINO L, BASSERMANN F, MAIOLICA A, LEE C, NOLAN PM, GODINHO SI, DRAETTA GF, PAGANO M: SCFFbxl3 controls the oscillation of the circadian clock by directing the degradation of cryptochrome proteins. Science 316: 900-904, 2007.

DAVIS FC, GORSKI RA: Development of hamster circadian rhythms: role of the maternal suprachiasmatic nucleus. J Comp Physiol A 162: 601-610, 1988.

DAVIS FC, MANNION J: Entrainment of hamster pup circadian rhythms by prenatal melatonin injections to the mother. Am J Physiol 255: R439-R448, 1988.

ETCHEGARAY JP, LEE C, WADE PA, REPPERT SM: Rhythmic histone acetylation underlies transcription in the mammalian circadian clock. Nature 421: 177-182, 2003.

FU L, LEE CC: The circadian clock: pacemaker and tumour suppressor. Nature Rev Cancer 3: 350-361, 2003.

GODINHO SI, MAYWOOD ES, SHAW L, TUCCI V, BARNARD AR, BUSINO L, PAGANO M, KENDALL R, QUWAILID MM, ROMERO MR, O'NEILL J, CHESHAM JE, BROOKER D, LALANNE Z, HASTINGS MH, NOLAN PM: The after-hours mutant reveals a role for Fbxl3 in determining mammalian circadian period. Science 316: 897-900, 2007.

HARMAR AJ, MARSTON HM, SHEN S, SPRATT C, WEST KM, SHEWARD WJ, MORRISON CF, DORIN JR, PIGGINS HD, REUBI JC, KELLY JS, MAYWOOD ES, HASTINGS MH: The VPAC $_{2}$ receptor is essential for circadian function in the mouse suprachiasmatic nuclei. Cell 109: 497-508, 2002.

HASTINGS MH, REDDY AB, MAYWOOD ES: A clockwork web: circadian timing in brain and periphery, in health and disease. Nat Rev Neurosci 4: 649-661, 2003.

CHENG HY, PAPP JW, VARLAMOVA O, DZIEMA H, RUSSELL B, CURFMAN JP, NAKAZAWA T, SHIMIZU K, OKAMURA H, IMPEY S, OBRIETAN K: microRNA modulation of circadian-clock period and entrainment. Neuron 54: 813-829, 2007.

INAGAKI N, HONMA S, ONO D, TANAHASHI Y, HONMA K: Separate oscillating cell groups in mouse suprachiasmatic nucleus couple photoperiodically to the onset and end of daily activity. Proc Natl Acad Sci USA 104: 7664-7669, 2007.

IWASAKI Y, OISO Y, SAITO H, MAJZOUB JA: Positive and negative regulation of the rat vasopressin gene promoter. Endocrinology 138: 5266-5274, 1997.

JIN X, SHEARMAN LP, WEAVER DR, ZYLKA MJ, DE VRIES GJ, REPPERT SM: A molecular mechanism regulating rhythmic output from the suprachiasmatic circadian clock. Cell 96: 57-68, 1999.

JUD C, ALBRECHT U: Circadian rhythms in murine pups develop in absence of a functional maternal circadian clock. J Biol Rhythms 21: 149-154, 2006.

KO CH, TAKAHASHI JS: Molecular components of the mammalian circadian clock. Hum Mol Genet 15 (Spec No 2): R271-277, 2006.

KOVÁČIKOVÁ Z, SLÁDEK M, BENDOVÁ Z, ILLNEROVÁ H, SUMOVÁ A: Expression of clock and clock-driven genes in the rat suprachiasmatic nucleus during late fetal and early postnatal development. J Biol Rhythms 21: 140-148, 2006.

LEE C, ETCHEGARAY JP, CAGAMPANG FR, LOUDON AS, REPPERT SM: Posttranslational mechanisms regulate the mammalian circadian clock. Cell 107: 855-867, 2001.

LEE HS, BILLINGS HJ, LEHMAN MN: The suprachiasmatic nucleus: a clock of multiple components. J Biol Rhythms 18: 435-449, 2003.

LI X, DAVIS FC: Developmental expression of clock genes in the Syrian hamster. Dev Brain Res 158: 31-40, 2005. 
LIU AC, WELSH DK, KO CH, TRAN HG, ZHANG EE, PRIEST AA, BUHR ED, SINGER O, MEEKER K, VERMA IM, DOYLE FJ, 3RD, TAKAHASHI JS, KAY SA: Intercellular coupling confers robustness against mutations in the SCN circadian clock network. Cell 129: 605-616, 2007.

LOWREY PL, SHIMOMURA K, ANTOCH MP, YAMAZAKI S, ZEMENIDES PD, RALPH MR, MENAKER M, TAKAHASHI JS: Positional syntenic cloning and functional characterization of the mammalian circadian mutation tau. Science 288: 483-492, 2000.

MAYWOOD ES, REDDY AB, WONG GK, O'NEILL JS, O'BRIEN JA, MCMAHON DG, HARMAR AJ, OKAMURA H, HASTINGS MH: Synchronization and maintenance of timekeeping in suprachiasmatic circadian clock cells by neuropeptidergic signaling. Curr Biol 16: 599-605, 2006.

MOORE RY: Development of the suprachiasmatic nucleus. In: Suprachiasmatic Nucleus: The mind's Clock. DC KLEIN, RY MOORE, SM REPPERT (eds), Oxford University Press, New York, 1991, pp 197-216.

MOORE RY, SPEH JC, LEAK RK: Suprachiasmatic nucleus organization. Cell Tissue Res 309: 89-98, 2002.

OHNO T, ONISHI Y, ISHIDA N: The negative transcription factor E4BP4 is associated with circadian clock protein PERIOD2. Biochem Biophys Res Commun 354: 1010-1015, 2007.

OHTA H, HONMA S, ABE H, HONMA K: Effects of nursing mothers on rPer1 and rPer2 circadian expressions in the neonatal rat suprachiasmatic nuclei vary with developmental stage. Eur J Neurosci 15: 1953-1960, 2002.

OHTA H, HONMA S, ABE H, HONMA K: Periodic absence of nursing mothers phase-shifts circadian rhythms of clock genes in the suprachiasmatic nucleus of rat pups. Eur J Neurosci 17: 1628-1634, 2003.

PREITNER N, DAMIOLA F, LOPEZ-MOLINA L, ZAKANY J, DUBOULE D, ALBRECHT U, SCHIBLER U: The orphan nuclear receptor REV-ERB alpha controls circadian transcription within the positive limb of the mammalian circadian oscillator. Cell 110: 251-260, 2002.

RALPH MR, FOSTER RG, DAVIS FC, MENAKER M: Transplanted suprachiasmatic nucleus determines circadian period. Science 247: 975-978, 1990.

RASPE E, MAUTINO G, DUVAL C, FONTAINE C, DUEZ H, BARBIER O, MONTE D, FRUCHART J, FRUCHART JC, STAELS B: Transcriptional regulation of human Rev-erb alpha gene expression by the orphan nuclear receptor retinoic acid-related orphan receptor alpha. J Biol Chem 277: 49275-49281, 2002.

REPPERT SM, SCHWARTZ WJ: Maternal suprachiasmatic nuclei are necessary for maternal coordination of the developing circadian system. J Neurosci 6: 2724-2729, 1986.

REPPERT SM, SCHWARTZ WJ: The suprachiasmatic nuclei of the fetal rat: characterization of a functional circadian clock using ${ }^{14} \mathrm{C}$-labeled deoxyglucose. J Neurosci 4: 1677-1682, 1984.

REPPERT SM, UHL GR: Vasopressin messenger ribonucleic acid in supraoptic and suprachiasmatic nuclei: Appearance and circadian regulation during development. Endocrinology 120: 2483-2487, 1987.

REPPERT SM, WEAVER DR: Molecular analysis of mammalian circadian rhythms. Annu Rev Physiol 63: 647-676, 2001.

SAKAMOTO K, OISHI K, NAGASE T, MIYAZAKI K, ISHIDA N: Circadian expression of clock genes during ontogeny in the rat heart. Neuroreport 13: 1239-1242, 2002.

SATO TK, PANDA S, MIRAGLIA LJ, REYES TM, RUDIC RD, MCNAMARA P, NAIK KA, FITZGERALD GA, KAY SA, HOGENESCH JB: A functional genomics strategy reveals Rora as a component of the mammalian circadian clock. Neuron 43: 527-537, 2004.

SAXENA MT, ATON SJ, HILDEBOLT C, PRIOR JL, ABRAHAM U, PIWNICA-WORMS D, HERZOG ED: Bioluminescence imaging of period1 gene expression in utero. Mol Imaging 6: 68-72, 2007.

SHEARMAN LP, SRIRAM S, WEAVER DR, MAYWOOD ES, CHAVES I, ZHENG B, KUME K, LEE CC, VAN DER HORST GT, HASTINGS MH, REPPERT SM: Interacting molecular loops in the mammalian circadian clock. Science 288: 1013-1019, 2000.

SHIBATA S, MOORE RY: Development of neuronal activity in the rat suprachiasmatic nucleus. Brain Res 431: 311315, 1987.

SHIMOMURA H, MORIYA T, SUDO M, WAKAMATSU H, AKIYAMA M, MIYAKE Y, SHIBATA S: Differential daily expression of Per1 and Per2 mRNA in the suprachiasmatic nucleus of fetal and early postnatal mice. Eur J Neurosci 13: 687-693, 2001.

SCHIBLER U, SASSONE-CORSI P: A web of circadian pacemakers. Cell 111: 919-922, 2002. 
SIEPKA SM, YOO SH, PARK J, SONG W, KUMAR V, HU Y, LEE C, TAKAHASHI JS: Circadian mutant Overtime reveals F-box protein FBXL3 regulation of cryptochrome and period gene expression. Cell 129: 1011-1023, 2007.

SLÁDEK M, JINDRÁKOVÁ Z, BENDOVÁ Z, SUMOVÁ A: Postnatal ontogenesis of the circadian clock within the rat liver. Am J Physiol 292: R1224-R1229, 2007.

SLÁDEK M, SUMOVÁ A, KOVÁČIKOVÁ Z, BENDOVÁ Z, LAURINOVÁ K, ILLNEROVÁ H: Insight into molecular core clock mechanism of embryonic and early postnatal rat suprachiasmatic nucleus. Proc Natl Acad Sci USA 101: 6231-6236, 2004.

TO TL, HENSON MA, HERZOG ED, DOYLE FJ, 3RD: A molecular model for intercellular synchronization in the mammalian circadian clock. Biophys J 92: 3792-3803, 2007.

VAN DER HORST GT, MUIJTJENS M, KOBAYASHI K, TAKANO R, KANNO S, TAKAO M, DE WIT J, VERKERK A, EKER AP, VAN LEENEN D, BUIJS R, BOOTSMA D, HOEIJMAKERS JH, YASUI A: Mammalian Cry1 and Cry2 are essential for maintenance of circadian rhythms. Nature 398: 627-630, 1999.

VANDERLEEST HT, HOUBEN T, MICHEL S, DEBOER T, ALBUS H, VANSTEENSEL MJ, BLOCK GD, MEIJER JH: Seasonal encoding by the circadian pacemaker of the SCN. Curr Biol 17: 468-473, 2007.

WEAVER DR, REPPERT SM: Periodic feeding of SCN-lesioned pregnant rats entrains the fetal biological clock. Dev Brain Res 46: 291-296, 1989.

WEAVER DR, ROCA AL, REPPERT SM: c-fos and jun-B mRNAs are transiently expressed in fetal rodent suprachiasmatic nucleus following dopaminergic stimulation. Dev Brain Res 85: 293-297, 1995.

WEINERT D: Ontogenetic development of the mammalian circadian system. Chronobiol Int 22: 179-205, 2005.

YAMAGUCHI S, ISEJIMA H, MATSUO T, OKURA R, YAGITA K, KOBAYASHI M, OKAMURA H: Synchronization of cellular clocks in the suprachiasmatic nucleus. Science 302: 1408-1412, 2003.

YAMAMOTO T, NAKAHATA Y, SOMA H, AKASHI M, MAMINE T, TAKUMI T: Transcriptional oscillation of canonical clock genes in mouse peripheral tissues. BMC Mol Biol 5: 18, 2004.

YAN L, OKAMURA H: Gradients in the circadian expression of Per1 and Per2 genes in the rat suprachiasmatic nucleus. Eur J Neurosci 15: 1153-1162, 2002.

YAN L, SILVER R: Resetting the brain clock: Time course and localization of mPER1 and mPER2 protein expression in suprachiasmatic nuclei during phase shifts. Eur J Neurosci 19: 1105-1109, 2004.

YAN L, TAKEKIDA S, SHIGEYOSHI Y, OKAMURA H: Per1 and Per2 gene expression in the rat suprachiasmatic nucleus: circadian profile and the compartment-specific response to light. Neuroscience 94: 141-150, 1999.

YOO SH, YAMAZAKI S, LOWREY PL, SHIMOMURA K, KO CH, BUHR ED, SIEPKA SM, HONG HK, OH WJ, YOO OJ, MENAKER M, TAKAHASHI JS: PERIOD2:LUCIFERASE real-time reporting of circadian dynamics reveals persistent circadian oscillations in mouse peripheral tissues. Proc Natl Acad Sci USA 101: 5339-5346, 2004.

ZHENG B, ALBRECHT U, KAASIK K, SAGE M, LU W, VAISHNAV S, LI Q, SUN ZS, EICHELE G, BRADLEY A, LEE CC: Nonredundant roles of the mPer1 and mPer2 genes in the mammalian circadian clock. Cell 105: 683-694, 2001. 